\title{
Mechanism of Plasma Cholesteryl Ester Transfer in Hypertriglyceridemia
}

\author{
Christopher J. Mann, Frances T. Yen, Andrew M. Grant, " and Bernard E. Bihain \\ Division of Lipoprotein Metabolism and Pathophysiology, Department of Physiology, Louisiana State University Medical Center, \\ New Orleans, Louisiana 70112; and *Department of Clinical Biochemistry, Centre Hospitalier
}

Universitaire de Sherbrooke, Sherbrooke, Québec J1H 5N4, Canada

\begin{abstract}
Plasma net cholesteryl ester (CE) transfer and optimum cholesteryl ester transfer protein (CETP) activity were determined in primary hypertriglyceridemic $(n=11)$ and normolipidemic $(n=15)$ individuals. The hypertriglyceridemic group demonstrated threefold greater net CE transfer leading to enhanced accumulation of CE in VLDL. This increased net transfer was not accompanied by a change in CETP activity. In normolipidemia, but not in hypertriglyceridemia, net CE transfer correlated with VLDL triglyceride $(r=0.92, P<0.001)$. In contrast, net CE transfer in hypertriglyceridemia, but not in normolipidemia, correlated with CETP activity $(r=0.73, P<0.01)$. Correction of hypertriglyceridemia with bezafibrate reduced net $\mathbf{C E}$ transfer towards normal and restored the correlation with VLDL triglyceride $(r=0.90, P<0.005)$ while suppressing the correlation with CETP activity. That net $\mathrm{CE}$ transfer depends on VLDL concentration was confirmed by an increase of net $\mathrm{CE}$ transfer in normolipidemic plasma supplemented with purified VLDL. Supplementation of purified CETP to normolipidemic plasma did not stimulate net $\mathbf{C E}$ transfer. In contrast, net $\mathbf{C E}$ transfer was enhanced by addition of CETP to both plasma supplemented with VLDL and hypertriglyceridemic plasma. Thus, in normal subjects, VLDL concentration determines the rate of net CE transfer. CETP becomes rate limiting as VLDL concentration increases, i.e., in hypertriglyceridemia. (J. Clin. Invest. 1991. 88:2059-2066.) Key words: cholesteryl ester transfer protein - very low density lipoprotein • high density lipoprotein • cardiovascular disease • reverse cholesterol transport
\end{abstract}

\section{Introduction}

In normal human plasma, neutral lipids, i.e., cholesteryl ester $(\mathrm{CE})^{1}$ and triglyceride ( $\mathrm{Tg}$ ) are redistributed between lipopro-

This work was performed at the Department of Physiology, Louisiana State University Medical Center, and the Department of Chemical Pathology, Leeds General Infirmary, Leeds, England. A portion of this paper has been presented as an abstract for the American Heart Association's 64th Scientific Session, Anaheim, CA, 11-14 Nov. 1991, and was published in abstract form (1991. Arteriosclerosis. 11: 1409a.)

Address reprint requests to Dr. C. J. Mann, Department of Physiology, Louisiana State University Medical Center, 1542 Tulane Avenue, New Orleans, LA 70112-2822. 1991

Received for publication 26 April 1991 and in revised form 1 August

1. Abbreviations used in this paper: CE, cholesteryl ester; CETP, CE transfer protein; E600, di-ethyl 4-nitrophenyl phosphate; LCAT, lecithin-cholesterol acyltransferase; $\mathrm{Tg}$, triglyceride.

J. Clin. Invest.

(c) The American Society for Clinical Investigation, Inc.

$0021-9738 / 91 / 12 / 2059 / 08 \quad \$ 2.00$

Volume 88, December 1991, 2059-2066 teins by cholesteryl ester transfer protein (CETP) $(1,2$; see ref. 3 for review). Kinetic data (4) and in vitro studies (5) indicate that transfer of HDL CE, derived from the lecithin-cholesterol acyltransferase (LCAT) reaction, to lower density, apo B-containing lipoproteins is an important route for clearance of $\mathrm{HDL}$ $\mathrm{CE}$. However, the absence of premature atherosclerosis in subjects with markedly increased HDL levels caused by CETP deficiency (null phenotype) $(6,7)$ suggests that the action of CETP could promote atherogenesis. Low plasma HDL concentration, which is an important predictor of coronary heart disease risk (8-10), is commonly observed in hypertriglyceridemic subjects. Since HDL cholesterol concentration is inversely related to plasma $\mathrm{Tg}$ levels $(11,12)$, the low HDL cholesterol levels in hypertriglyceridemia could result from an increased rate of CE transfer from HDL to $\mathrm{Tg}$-rich lipoproteins.

Consistent with this analysis, previous studies have shown that compared to normal, hypertriglyceridemic HDL are CE depleted and $\mathrm{Tg}$ enriched, while VLDL are enriched with CE (13). In contrast, plasma incubation studies have shown that in hypertriglyceridemic subjects with vascular disease, the rate of net CE transfer from HDL to apo B-containing lipoproteins is reduced (5). This observation suggests that the apoB-containing lipoproteins of these subjects display impaired ability to accept CE from $\operatorname{HDL}(5,14)$. Recent investigations, however, have shown that apo B-containing lipoproteins of hypertriglyceridemic subjects accept HDL CE at a rate comparable with normal subjects (15). Also, net CE transfer has been reported to be enhanced in other conditions of hypertriglyceridemia, i.e., dysbetalipoproteinemia (16), and postprandial lipemia $(17,18)$. To address this controversial issue, we investigated the mechanism of CETP-mediated transfer of CE in a homogeneous group of subjects with primary hypertriglyceridemia, and in a control group of normolipidemic subjects matched for age and sex.

In this paper, we report that in primary hypertriglyceridemia, the rate of CE accumulation in VLDL is increased threefold compared to normolipidemia. This enhanced net $\mathrm{CE}$ transfer does not result from a change in optimum CETP activity, but rather from an increase in VLDL concentration.

\section{Methods}

Materials. $\left[1 \alpha, 2 \alpha(\mathrm{n})^{3} \mathrm{H}\right]$ Cholesterol (sp act, $45.6 \mathrm{Ci} / \mathrm{mmol}$ ) was obtained from Amersham International, Amersham, Buckinghamshire, England. Phenyl-Sepharose CL4B and DEAE Sepharose CL6B were from Pharmacia Fine Chemicals, Uppsala, Sweden. Cholesterol (C-system CHOD-PAP), unesterified cholesterol (CHOD-PAP), and triglyceride (GPO-PAP) enzymatic reagents, standards, and control sera were purchased from Boehringer Mannheim, London, England. Apoprotein-measuring kits (Orion Diagnostica) were obtained from Unipath, Basingstoke, England. Di-ethyl 4-nitrophenyl phosphate (E600), heparin (porcine intestinal mucosa, sodium salt), aprotinin, and all other reagents were from Sigma Chemical Co., Dorset, England, or St. Louis, MO. Bezafibrate (2-[4-[2-[(4-chlorobenzoyl)amino]-ethyl]phenoxy]-2methylpropanoic acid) was obtained from Boehringer Mannheim (formerly MCP Pharmaceuticals), Livingstone, Scotland. 
Subjects. This study involved the participation of informed, consenting adult human subjects. Hypertriglyceridemic patients (VLDL $\mathrm{Tg}>1.5 \mathrm{mmol} /$ liter or $130 \mathrm{mg} / \mathrm{dl}$ ) attending Leeds General Infirmary Lipid Clinic, Leeds, England, were screened for secondary causes of hyperlipidemia. Subjects with glucose intolerance, liver or kidney disease, thyroid dysfunction, or alcoholism were excluded. To ensure a homogeneous population, those individuals with raised LDL (1.006 $<d<1.063 \mathrm{~g} / \mathrm{ml}$ ) cholesterol concentration $(>4.2 \mathrm{mmol} /$ liter or 160 $\mathrm{mg} / \mathrm{dl}$ ) were also excluded from the study. Of the 11 selected hypertriglyceridemic subjects, none had taken lipid-active medication in the previous four months, and each was following lipid clinic dietary guidance. 8 of these 11 subjects, diagnosed with $(n=4)$ or having family history of $(n=4)$ cardiovascular disease, were restudied after 6 wk treatment with bezafibrate ( $200 \mathrm{mg}$, three times per day). The criterion for positive family history was diagnosis of cardiovascular disease in first or second degree relatives: one before age 50 , two before age 60 , or three before age 65.15 normolipidemic control subjects (LDL cholesterol $\leq 4.2 \mathrm{mmol} /$ liter, and VLDL Tg $\leq 1.2 \mathrm{mmol} /$ liter or $110 \mathrm{mg} / \mathrm{dl}$ ) were matched for age and sex.

Sample preparation. After an overnight fast, blood was collected into tubes containing disodium EDTA (final concentration, $1 \mathrm{mg} / \mathrm{ml}$ ) at $4^{\circ} \mathrm{C}$. Aprotinin $(0.14 \mathrm{IU} / \mathrm{ml}$ ) and $\mathrm{E} 600$ (di-ethyl 4-nitrophenyl phosphate) ( $2 \mathrm{mM}$, final concentration) were added to all plasma samples to inhibit protease and LCAT activities, respectively.

Measurement of lipids and apoproteins. Concentrations of plasma and lipoprotein total cholesterol, unesterified cholesterol, and triglyceride were measured using enzymatic reagents, and are expressed as millimoles per liter using molecular weights of 387 for cholesterol and 885 for triglyceride. CE was calculated as the difference between measured total and unesterified cholesterol concentrations. HDL total and unesterified cholesterol were determined in plasma after precipitation of apo B-containing lipoproteins with sodium heparin ( $250 \mathrm{U} / \mathrm{ml}$ plasma) and $\mathrm{MnCl}_{2}\left(92 \mathrm{mM}\right.$, final concentration) at $4^{\circ} \mathrm{C}(19)$. To prevent interference of excess manganese ions with these lipid determinations, the enzymatic reagents were first supplemented with 8 mM EDTA. Concentrations of apoproteins AI and B in plasma were determined by immunoturbidimetric methods. Protein was determined by the method of Lowry et al. (20) using BSA as standard.

Isolation of lipoprotein fractions. VLDL and LDL were obtained from individual plasma samples $(1-1.5 \mathrm{ml})$ by sequential ultracentrifugation. VLDL $(d<1.006 \mathrm{~g} / \mathrm{ml})$ was isolated using a rotor (TFT 80.4; Sorvall Instruments Div., part of DuPont Co., Newton, CT) at 310,000 $g$ for $4 \mathrm{~h} 10 \mathrm{~min}$ at $4^{\circ} \mathrm{C}$. LDL $(1.006<d<1.063 \mathrm{~g} / \mathrm{ml})$ was isolated by a second centrifugation at $265,000 \mathrm{~g}$ for $7 \mathrm{~h} 10 \mathrm{~min}$ at $4^{\circ} \mathrm{C}$.

Lipoproteins isolated for preparative purposes were obtained by sequential ultracentrifugation using a rotor (Ti50.2; Beckman Instruments, Fullerton, CA) at $145,000 \mathrm{~g}$ and $4^{\circ} \mathrm{C}: \operatorname{VLDL}(d<1.006 \mathrm{~g} / \mathrm{ml}, 18$ h), LDL $(1.006<d<1.063 \mathrm{~g} / \mathrm{ml}, 24 \mathrm{~h})$, HDL $(1.063<d<1.21 \mathrm{~g} / \mathrm{ml}$, $48 \mathrm{~h}$ ). Each fraction was concentrated by subsequent flotation using a rotor (SW40; Beckman Instruments) at $4^{\circ} \mathrm{C}$. Isolated fractions were dialyzed against buffer containing $50 \mathrm{mM}$ Tris, $150 \mathrm{mM} \mathrm{NaCl}, 2 \mathrm{mM}$ EDTA, pH 7.4, and then stored at $4^{\circ} \mathrm{C}$ in the presence of aprotinin $(0.14 \mathrm{IU} / \mathrm{ml})$. All preparations were used within $48 \mathrm{~h}$.

Determination of net CE transfer in plasma. Net CE transfer was measured as the change of CE concentration in VLDL and LDL fractions after in vitro incubation of plasma, unless otherwise indicated. Fresh plasma samples (1-1.5 ml) capped under nitrogen were incubated at $37^{\circ} \mathrm{C}$ for the indicated times, and the reaction was terminated by chilling on ice. VLDL and LDL fractions were isolated as described above. Each sample was analyzed twice and all lipid measurements were in quadruplicate, unless otherwise indicated. Since CETP activity is negligible at $4^{\circ} \mathrm{C}(21)$, corresponding samples incubated at this temperature served as controls. Fig. 1 shows the linearity with time of net CE transfer to VLDL in normolipidemic and hypertriglyceridemic plasma.

Determination of optimum CETP activity. CETP activity was measured under conditions that optimize the unidirectional movement of radiolabeled CE between donor (HDL) and acceptor (LDL), i.e., as a

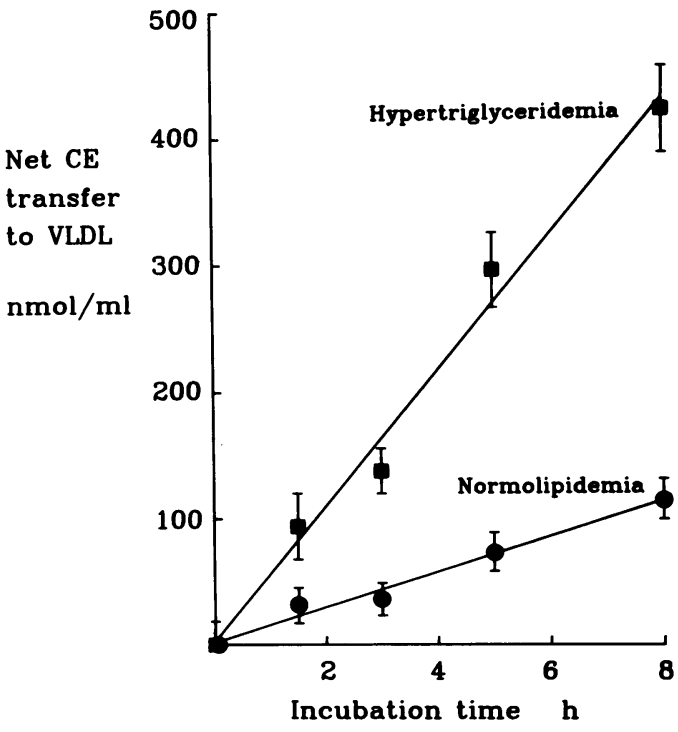

Figure 1. Net CE transfer to VLDL in normolipidemic and hypertriglyceridemic plasma over time. Normolipidemic subject: cholesterol $4.9 \mathrm{mmol} / \mathrm{liter}(190 \mathrm{mg} / \mathrm{dl}), \mathrm{Tg} 0.6 \mathrm{mmol} / \mathrm{liter}(53 \mathrm{mg} / \mathrm{dl})$ and HDL cholesterol $1.38 \mathrm{mmol} / \mathrm{liter}(53 \mathrm{mg} / \mathrm{dl})$. Hypertriglyceridemic subject: cholesterol $8.1 \mathrm{mmol} /$ liter $(313 \mathrm{mg} / \mathrm{dl}), \mathrm{Tg} 3.8 \mathrm{mmol} /$ liter $(336 \mathrm{mg} / \mathrm{dl})$ and HDL cholesterol $1.10 \mathrm{mmol} / \mathrm{liter}(43 \mathrm{mg} / \mathrm{dl})$. Aliquots of fasting plasma $(1.5 \mathrm{ml})$ were incubated at $37^{\circ} \mathrm{C}$ for $1.5,3,5$, and $8 \mathrm{~h}$ in the presence of the LCAT inhibitor, E600 (final concentration, $2 \mathrm{mM})$. VLDL $(d<1.006 \mathrm{~g} / \mathrm{ml})$ was isolated from each aliquot using a Sorvall TFT 80.4 rotor at $310,000 \mathrm{~g}$ for $4 \mathrm{~h} 10 \mathrm{~min}$ at $4^{\circ} \mathrm{C}$. Net $\mathrm{CE}$ transfer was determined as the accumulation of $\mathrm{CE}$ in VLDL, relative to VLDL from a control aliquot incubated at $4^{\circ} \mathrm{C}$ (mean \pm SD, quadruplicate determinations).

measure of plasma CETP mass. ${ }^{3} \mathrm{H}-\mathrm{CE}-\mathrm{HDL}_{3}(1.125<d<1.21 \mathrm{~g} / \mathrm{ml})$ were prepared according to Albers et al. (2). Plasma ( $5 \mu \mathrm{l})$ was incubated for $3 \mathrm{~h}$ at $37^{\circ} \mathrm{C}$ with ${ }^{3} \mathrm{H}-\mathrm{CE}-\mathrm{HDL}_{3}(25 \mathrm{nmol} \mathrm{CE})$ and unlabeled $\mathrm{LDL}(500 \mathrm{nmol} \mathrm{CE})$ in buffer containing $50 \mathrm{mM}$ Tris, $150 \mathrm{mM} \mathrm{NaCl}, 2$ mM EDTA, pH 7.4 (final vol, $100 \mu$ l). After incubation, LDL was removed by heparin/ $\mathrm{MnCl}_{2}$ precipitation, and CETP activity was determined as the loss of ${ }^{3} \mathrm{H}-\mathrm{CE}$ from the HDL supernatant, compared to a blank incubated for the same time without plasma. Each plasma and blank was assayed in quadruplicate. Transfer of labeled substrate did not exceed $25 \%$ per incubation. Fig. 2 shows that under the conditions described, movement of ${ }^{3} \mathrm{H}-\mathrm{CE}$ from donor to acceptor lipoproteins was dependent on CETP mass (Fig. $2 A$ ) and time of incubation (Fig. 2 B).

Purification of CETP. Human plasma CETP was purified 500-fold from blood bank plasma $(800 \mathrm{ml})$. Plasma $(d=1.21 \mathrm{~g} / \mathrm{ml})$ was centrifuged in a rotor (Ti50.2; Beckman) at $145,000 \mathrm{~g}$ for $48 \mathrm{~h}$ at $4^{\circ} \mathrm{C}$. The clear middle zone, which contained $>70 \%$ of total plasma CETP activity, was directly applied to a $45 \times 2.5 \mathrm{~cm}$ column of phenyl-Sepharose CL4B equilibrated in $10 \mathrm{mM}$ Tris, $3 \mathrm{M} \mathrm{NaCl}, \mathrm{pH}$ 7.4. The column was washed with 5 bed vol of buffer containing $10 \mathrm{mM}$ Tris, $150 \mathrm{mM} \mathrm{NaCl}$, pH 7.4. Bound material was then eluted with distilled water containing $3 \mathrm{mM}$ sodium azide, $\mathrm{pH}$ 7.4. Fractions with CETP activity were pooled, dialyzed against $10 \mathrm{mM}$ Tris, $\mathrm{pH} 7.4$, and then applied to a 25 $\times 1.5 \mathrm{~cm}$ column of DEAE Sepharose CL6B equilibrated with the same buffer. Elution was with a linear gradient $(600 \mathrm{ml})$ of $0-250 \mathrm{mM} \mathrm{NaCl}$ in $10 \mathrm{mM}$ Tris, $\mathrm{pH}$ 7.4. CETP-containing fractions, which eluted between 95 and $130 \mathrm{mM} \mathrm{NaCl}$, were pooled and concentrated by negative pressure dialysis (Bio-Molecular Dynamics, Beaverton, $O R$ ). Buffers used in the purification contained $2 \mathrm{mM}$ EDTA, and all procedures were at $4^{\circ} \mathrm{C}$. The partially purified CETP (optimum CETP activity: $750 \mathrm{nmol} \mathrm{CE}$ transferred/h $\cdot \mathrm{mg}$ protein) in buffer containing 10 

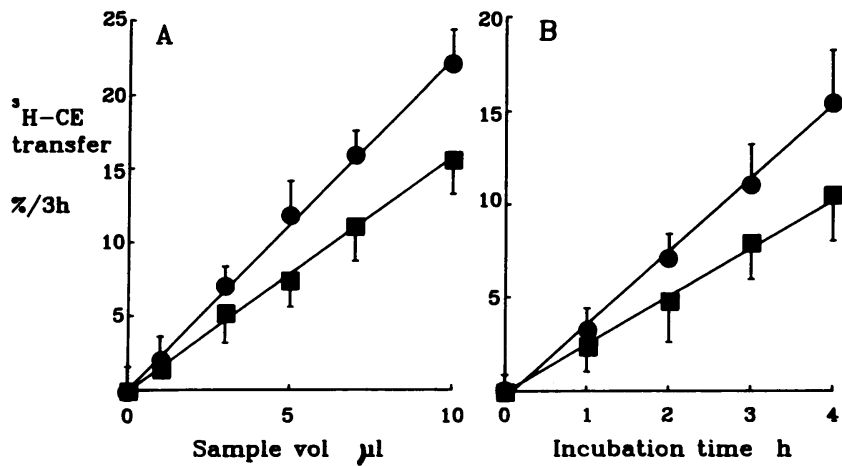

Figure 2. Relationship of CETP activity assay to CETP concentration $(A)$ and incubation time $(B)$. $(A)$ Volumes of up to $10 \mu$ l of normolipidemic plasma $(\bullet)$ or purified CETP $(a, 200 \mu \mathrm{g}$ protein $/ \mathrm{ml})$ were in cubated for $3 \mathrm{~h}$ at $37^{\circ} \mathrm{C}$ with ${ }^{3} \mathrm{H}-\mathrm{CE}-\mathrm{HDL}_{3}(25 \mathrm{nmol} \mathrm{CE})$ and unlabeled LDL ( $500 \mathrm{nmol} \mathrm{CE}$ ) in $50 \mathrm{mM}$ Tris, $150 \mathrm{mM} \mathrm{NaCl}, 2 \mathrm{mM}$ EDTA, pH 7.4 in a final vol of $100 \mu \mathrm{l}$. (B) $5 \mu \mathrm{l}$ of normolipidemic plasma (๑) or purified CETP ( $\bullet$ ) were incubated under the same conditions as in $A$ for the indicated times. After the incubations, LDL were precipitated using heparin and $\mathrm{MnCl}_{2}$. CETP activity was determined from the loss of ${ }^{3} \mathrm{H}-\mathrm{CE}$ from the HDL supernatant, minus the loss from blank samples incubated for the same time without plasma or purified CETP. Points are expressed as mean \pm SD of quadruplicate determinations.

$\mathrm{mM}$ Tris, $150 \mathrm{mM} \mathrm{NaCl}, 2 \mathrm{mM}$ EDTA, $\mathrm{pH} 7.4$, was aliquoted and stored at $-70^{\circ} \mathrm{C}$. No LCAT activity (22) was detectable in this fraction.

Statistical analyses. Statistical significance of the differences between two means was determined by two-tailed Student's $t$ test for paired or unpaired samples as indicated. Correlations were analyzed using linear Pearson correlation coefficient.

\section{Results}

Increased net CE transfer in hypertriglyceridemic subjects does not result from changes in CETP activity. Compared to the normolipidemic group, hypertriglyceridemic subjects showed significantly higher VLDL Tg and significantly lower HDL cholesterol (Table I). Two parameters were determined to assess neutral lipid redistribution between lipoprotein subfractions. Net CE transfer was measured as the change of CE concentration in VLDL and LDL fractions following whole plasma incubations. Plasma optimum CETP activity was measured under conditions that minimize the relative effects of donor and acceptor lipoproteins. The latter parameter provides a measure of CETP mass (23). In the hypertriglyceridemic group, net CE transfer was enhanced compared to normolipidemic subjects leading to a threefold increased accumulation of CE in VLDL (Table I). Net CE transfer to LDL was not significantly increased in hypertriglyceridemia. For both normolipidemic and hypertriglyceridemic subjects, net CE transfer to VLDL was accompanied by an equivalent molar net $\mathrm{Tg}$ transfer from VLDL (data not shown). There was no statistically significant increase in optimum CETP activity in hypertriglyceridemic plasma. These data suggested that net transfer of neutral lipids is accelerated in hypertriglyceridemia, but does not result from an increase in plasma CETP mass.

Net CE transfer correlates with plasma VLDL triglyceride concentration only in the normolipidemic group. The observation that CETP activity is normal in hypertriglyceridemia led us to question the ability of lipoprotein neutral lipid levels to modulate the rate of net $\mathrm{CE}$ transfer. Since net $\mathrm{CE}$ transfer to
LDL was small, and not statistically different between the two groups studied, we analyzed potential relationships of net $\mathrm{CE}$ transfer with lipoprotein CE donor (HDL) and acceptor (VLDL) concentrations. A positive linear correlation $(r=0.92$, $P<0.001$ ) between net CE transfer and VLDL Tg was found in the normolipidemic group (Fig. $3 A$ ) but not in the hypertriglyceridemic group (Fig. $3 B$ ). The correlation observed in normolipidemic subjects is consistent with data reported previously in 15 other normolipidemic controls (24). No statistically significant correlation could be found in either group, between net $C E$ transfer and HDL CE concentration (Fig. 3, $C$ and $D$ ). These results suggested that in normolipidemia, the concentration of CE acceptor (VLDL), rather than CE donor (HDL), determines the rate of net $\mathrm{CE}$ transfer. For the hypertriglyceridemic group, however, the absence of significant correlations between net $\mathrm{CE}$ transfer and either acceptor or donor lipoprotein lipid concentrations indicated that the rate of net $C E$ transfer is independent of plasma lipid levels in these subjects.

Net CE transfer correlates with CETP activity only in the hypertriglyceridemic group. We next questioned whether in hypertriglyceridemia the rate of net $\mathrm{CE}$ transfer is related to CETP mass. Fig. 4 shows that, in contrast with the normolipidemic group (Fig. $4 \mathrm{~A}$ ), the hypertriglyceridemic group (Fig. 4 $B$ ) displayed a positive significant correlation between net $\mathrm{CE}$ transfer and optimum CETP activity. Taken together, these observations led us to hypothesize that: $(a)$ the rate of net CE transfer in normolipidemia is limited by $\mathrm{Tg}$-rich acceptor-lipoprotein concentration; and $(b)$ in hypertriglyceridemia, enhanced net CE transfer as a result of raised VLDL concentration, is limited by the normal CETP mass in these subjects.

Supplementation of normolipidemic plasma with normal $V L D L$ increases net CE transfer. To test whether net CE transfer is determined by VLDL concentration, we created conditions of hypertriglyceridemia in vitro by supplementing

Table I. Plasma Lipids, Apolipoproteins, and CE Transfer Measurements of Normal and Hypertriglyceridemic Subjects

\begin{tabular}{lcc}
\hline & Normolipidemic & Hypertriglyceridemic \\
\hline Number of subjects & 15 & 11 \\
Sex (Male/Female) & $11 / 4$ & $8 / 3$ \\
Age (yr) & $48.2 \pm 7.8^{*}$ & $51.6 \pm 7.1$ \\
Cholesterol (mmol/liter) & $5.2 \pm 0.7$ & $6.1 \pm 0.6^{\ddagger}$ \\
Triglycerides (mmol/liter) & $1.19 \pm 0.46$ & $3.71 \pm 0.97^{\S}$ \\
VLDL-Triglycerides & & \\
$\quad$ (mmol/liter) & $0.64 \pm 0.39$ & $2.80 \pm 0.63^{\S}$ \\
HDL-Cholesterol & & \\
$\quad$ (mmol/liter) & $1.41 \pm 0.34$ & $0.93 \pm 0.16^{\S}$ \\
LDL-Cholesterol (mmol/liter) & $3.41 \pm 0.52$ & $3.37 \pm 0.70$ \\
Apo AI (mg/ml) & $1.28 \pm 0.22$ & $1.03 \pm 0.10^{\S}$ \\
Apo B (mg/ml) & $0.88 \pm 0.14$ & $1.17 \pm 0.17^{11}$ \\
Net CE transfer & & \\
$\quad$ (nmol/ml 6 h) & & \\
to VLDL & & \\
to LDL & $101.1 \pm 58.0$ & $345.4 \pm 52.4^{\S}$ \\
Optimum CETP Activity & $15.7 \pm 28.9$ & $30.8 \pm 68.5$ \\
$\quad(\mathrm{nmol} / \mathrm{ml} \cdot \mathrm{h})$ & & \\
\end{tabular}

* Mean \pm SD. ${ }^{8} P<0.001 ;{ }^{*} P<0.01 ;$ " $P<0.05$ vs. normolipidemic (unpaired $t$ test). 
NORMOLIPIDEMLA
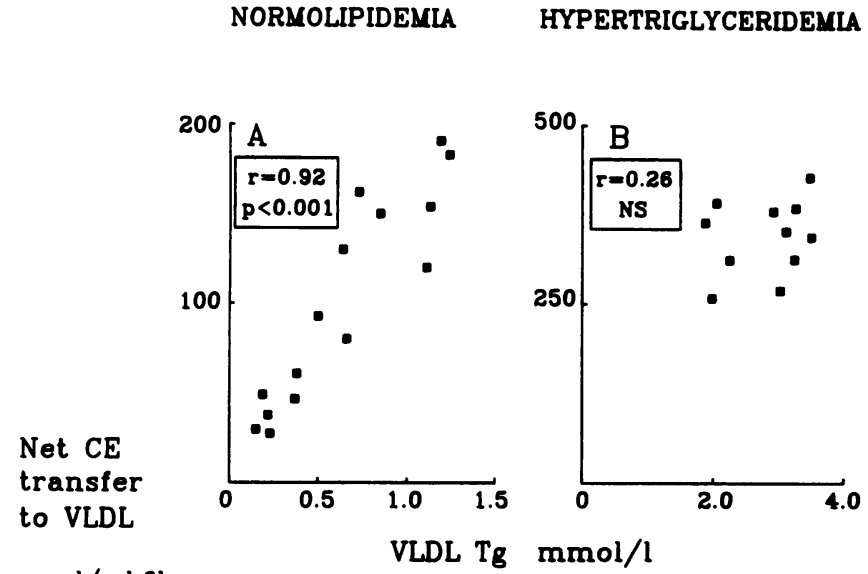

$\mathrm{nmol} / \mathrm{ml} .6 \mathrm{~h}$

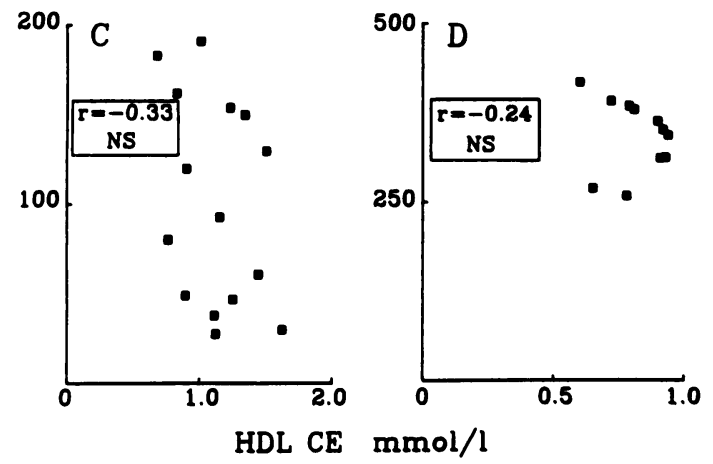

Figure 3. Correlations of plasma net CE transfer to VLDL with VLDL $\operatorname{Tg}(A$ and $B)$ and HDL CE ( $C$ and $D)$ in normolipidemic and hypertriglyceridemic subjects.

normolipidemic plasma with increasing concentrations of VLDL isolated from a normolipidemic subject. Fig. 5 shows net CE transfer to VLDL as a function of VLDL concentration. For VLDL Tg within the normal range (i.e., $\leq 1.2 \mathrm{mmol} /$ liter or $110 \mathrm{mg} / \mathrm{dl}$ ), net CE transfer increased with VLDL Tg concentration. Beyond normal VLDL levels, net CE transfer tended to plateau as the rate approached plasma optimum CETP activity. These data show that supplementation of normolipidemic plasma with excess normal VLDL can induce a threefold increase in net $\mathrm{CE}$ transfer, consistent with the enhancement of net $\mathrm{CE}$ transfer observed in hypertriglyceridemic subjects.

Supplementation of VLDL-enriched normolipidemic plasma or hypertriglyceridemic plasma with CETP further increases net $C E$ transfer. To test that CETP concentration limits net $\mathrm{CE}$ transfer in conditions of excess $\mathrm{Tg}$-rich acceptor, normolipidemic plasma (VLDL Tg $=0.38 \mathrm{mmol} / \mathrm{liter}, 34 \mathrm{mg} / \mathrm{dl}$ ) and the same plasma enriched with normal VLDL (VLDL Tg $=5 \mathrm{mmol} /$ liter, $440 \mathrm{mg} / \mathrm{dl}$ ) were supplemented with partially purified CETP. Fig. 6 shows that addition of CETP enhanced net $C E$ transfer in VLDL-enriched plasma, but not in normolipidemic plasma. The inset of Fig. 6 demonstrates that the optimum CETP activities in both VLDL-rich and normal plasma increased linearly with the addition of CETP. Thus, the inability of CETP to increase net CE transfer in normal plasma is consistent with this protein being in excess in normolipidemic subjects.

To further test the hypothesis that CETP is rate limiting in hypertriglyceridemia, hypertriglyceridemic plasma were sup-

plemented with CETP. Consistent with that observed in VLDL-enriched plasma (Fig. 6), CETP supplementation of hypertriglyceridemic plasma further increased the initially high rate of net CE transfer (Table II).

Taken together, these data show that VLDL concentration limits net CE transfer in normolipidemic conditions. CETP becomes rate limiting only in the presence of an excess of $\mathrm{Tg}$ rich lipoprotein.

Effect on net CE transfer of supplementing normolipidemic plasma with purified normal HDL or LDL. To define the roles of HDL and LDL in determining the rate of net CE transfer, we supplemented plasma with increasing concentrations of these lipoproteins isolated from the same subject (Fig. 7). Fig. $7 \mathrm{~A}$ shows that net CE transfer to VLDL was not enhanced by supplementation of HDL to: $(a)$ normolipidemic plasma; $(b)$ plasma enriched to $5 \mathrm{mmol} / \mathrm{liter}$ VLDL Tg; or (c) VLDLenriched plasma with twofold increased CETP activity. Fig. 7 B shows that supplementation with LDL tended to increase net CE transfer. However, this increase reached statistical significance $(P<0.05$, two-tailed, paired $t$ test) only at the highest concentration of LDL (12.4 mmol/liter cholesterol) in plasma enriched with both VLDL ( $5 \mathrm{mmol} /$ liter VLDL Tg) and CETP (twofold CETP activity). These data therefore support the notion that neither HDL nor LDL is a primary determinant of net CE transfer.

Correction of hypertriglyceridemia with bezafibrate suppresses the correlation of net CE transfer with CETP activity and restores correlation with plasma VLDL triglyceride. To further test our hypothesis, we investigated the effect of correcting hypertriglyceridemia on the relationships of net CE transfer with CETP activity, and with donor and acceptor lipoprotein levels. 8 of the 11 hypertriglyceridemic subjects, considered to require a lipid lowering drug based on diagnosis or strong family history of cardiovascular disease, were treated with bezafibrate. Six weeks after treatment, both plasma and VLDL Tg were significantly reduced and HDL cholesterol was significantly increased (Table III). Net CE transfer was reduced to half the pretreatment level as a consequence of significantly less accumulation of CE in the VLDL fraction (Table III). Bezafibrate did not alter plasma CETP activity. These data support the concept that net $\mathrm{CE}$ transfer can be altered without change in plasma CETP mass.

In further analysis, we compared the correlations of net $\mathrm{CE}$ transfer to VLDL with CETP activity, VLDL Tg, and HDL CE

A NORMOLIPIDEMIA

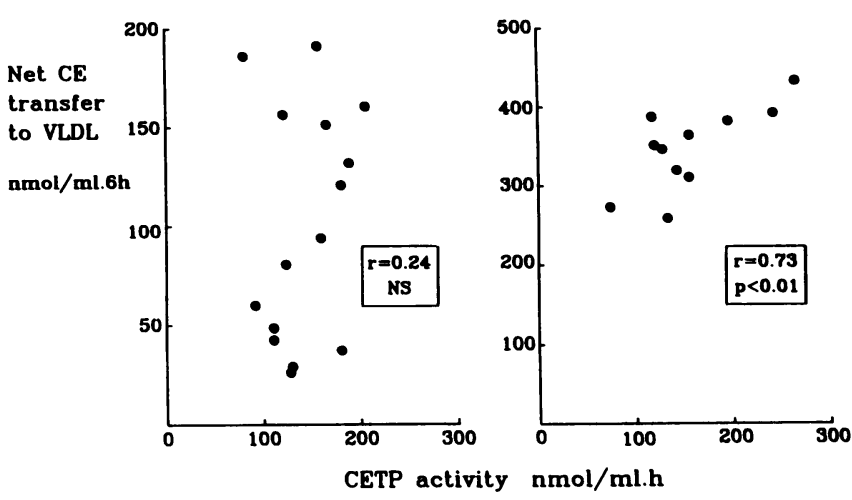

Figure 4. Correlations of plasma net CE transfer to VLDL with plasma optimum CETP activity in normolipidemic $(A)$ and hypertriglyceridemic $(B)$ subjects. 


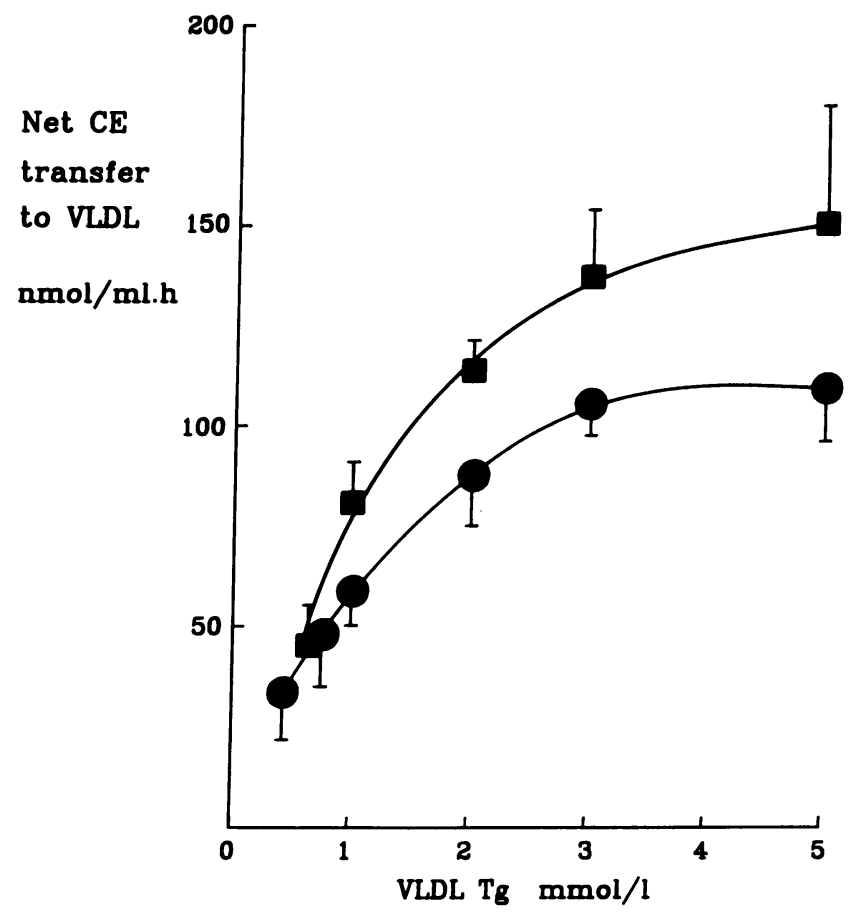

Figure 5. Effect on net CE transfer of increasing concentrations of normal VLDL in whole normolipidemic plasma. Fasting plasma was obtained from two subjects: subject 1 ( $\square$ )-cholesterol $5.4 \mathrm{mmol} /$ liter $(209 \mathrm{mg} / \mathrm{dl}), \mathrm{Tg} 1.2 \mathrm{mmol} / \mathrm{liter}(106 \mathrm{mg} / \mathrm{dl})$, and HDL cholesterol $1.09 \mathrm{mmol} /$ liter $(42 \mathrm{mg} / \mathrm{dl})$; subject $2(\bullet)$-cholesterol $3.3 \mathrm{mmol} /$ liter $(128 \mathrm{mg} / \mathrm{dl}), \mathrm{Tg} 0.54 \mathrm{mmol} / \mathrm{liter}(48 \mathrm{mg} / \mathrm{dl})$, and HDL cholesterol $1.21 \mathrm{mmol} /$ liter $(47 \mathrm{mg} / \mathrm{dl})$. Plasma CETP activities were 216 and 143 $\mathrm{nmol} / \mathrm{ml} \cdot \mathrm{h}$, respectively. $1-\mathrm{ml}$ aliquots from subjects 1 and 2 were incubated at $37^{\circ} \mathrm{C}$ for $2 \mathrm{~h}$ with or without increasing amounts of VLDL isolated from subject 1 . The LCAT inhibitor, E600 $(2 \mathrm{mM}$, final concentration) was included in the assay and the final volume was adjusted to $1.2 \mathrm{ml}$. Net CE transfer was measured as the loss of $\mathrm{CE}$ from the $d>1.006 \mathrm{~g} / \mathrm{ml}$ (HDL + LDL) fraction. Corresponding samples incubated at $4^{\circ} \mathrm{C}$ served as controls. Each point represents the mean $\pm \mathrm{SD}$ of quadruplicate determinations.

in the eight subjects before and after treatment. The significances of these correlations before treatment were not different from those observed in the 11 original subjects (Figs. 3 and 4). Fig. 8 shows the correlations after bezafibrate treatment. The correlation between net CE transfer and optimum CETP activity did not reach statistical significance (Fig. $8 \mathrm{~A}$ ), contrasting with the significant correlation observed prior to treatment. Concomitantly, a statistically significant correlation between net CE transfer and plasma VLDL Tg concentration was observed after bezafibrate treatment (Fig. $8 \mathrm{~B}$ ). The lack of correlation between net CE transfer and HDL CE observed before bezafibrate, persisted after therapy (Fig. $8 \mathrm{C}$ ). This showed that correction of hypertriglyceridemia with bezafibrate suppresses the relationship of net CE transfer with CETP activity, and restores the relationship with plasma VLDL $\mathrm{Tg}$. These data therefore further support the hypothesis that $\mathrm{Tg}$-rich lipoprotein concentration determines the rate of net $C E$ transfer in normolipidemia, while CETP limits net CE transfer in the presence of high VLDL concentrations.

\section{Discussion}

The data presented here show that in plasma from primary hypertriglyceridemic subjects, net CE transfer to VLDL is threefold faster than in normolipidemic individuals. In either group, CE did not accumulate in LDL. Our findings also show that optimum CETP activity, which provides a measure of CETP mass (23) is not concomitantly increased in hypertriglyceridemic plasma. This latter finding is in agreement with the observation that hypertriglyceridemic subjects have normal CETP mass as measured by radioimmunoassay (23).

Investigation of the factors determining net $C E$ transfer in normolipidemic and hypertriglyceridemic subjects provided a mechanism to explain the dissociation between rate of net $\mathrm{CE}$ transfer and CETP mass. Correlation analysis indicated that a direct relationship exists between plasma VLDL concentration and net $\mathrm{CE}$ transfer in normolipidemic subjects. The analysis further suggested that, in contrast to normal subjects, net $\mathrm{CE}$ transfer in hypertriglyceridemia is determined by CETP mass. A possible explanation for these different correlations was that in normolipidemia, CETP is in excess and VLDL concentration (i.e., availability of $\mathrm{Tg}$ ) limits the rate of net $\mathrm{CE}$ transfer, while in hypertriglyceridemia, where VLDL concentration is increased, net CE transfer is dependent on CETP mass.

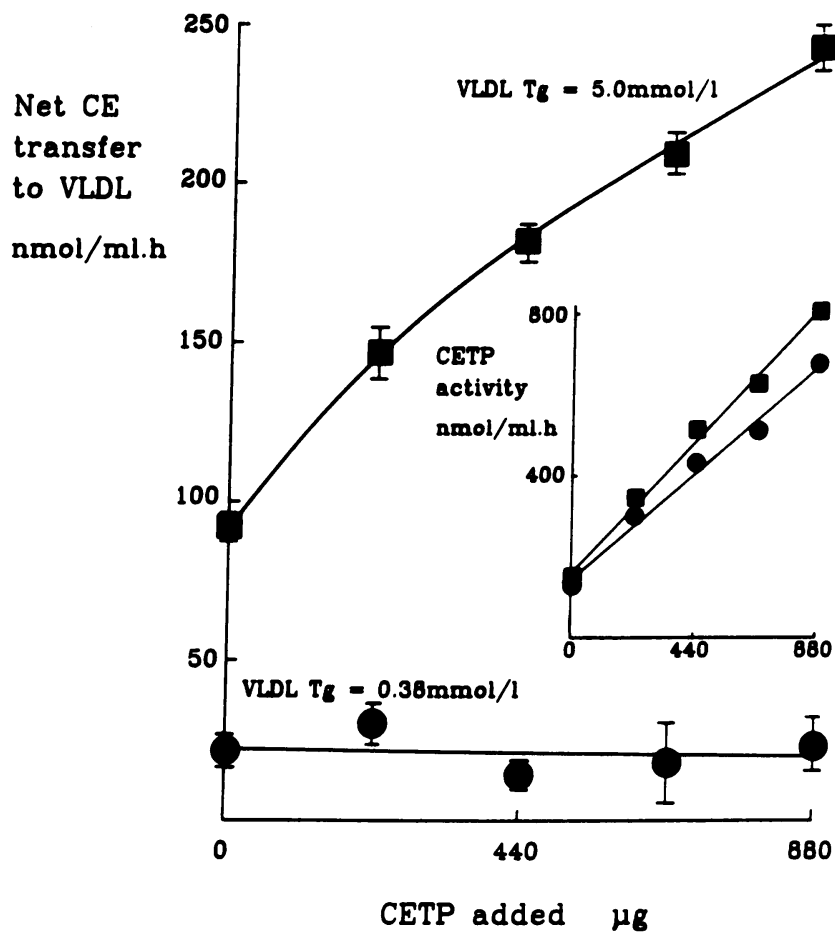

Figure.6. Effect on net CE transfer of CETP supplementation to plasma enriched ( $($ ) or not ( $\bullet$ ) with normal VLDL. Using the same subjects as in Fig. 5, fasting 1-ml plasma aliquots from subject 2 were enriched or not with VLDL from subject 1, then supplemented or not (first point) with increasing concentrations of purified ( 500 -fold) CETP in a final vol of $1.4 \mathrm{ml}$. These samples were incubated at $37^{\circ} \mathrm{C}$ for either $4 \mathrm{~h}$ (normolipidemic plasma) or $2 \mathrm{~h}$ (VLDL-enriched plasma). All samples contained LCAT inhibitor ( $2 \mathrm{mM}$ E600, final concentration) and corresponding samples incubated at $4^{\circ} \mathrm{C}$ served as controls. Net CE transfer was measured as loss of CE from the $d$ $>1.006 \mathrm{~g} / \mathrm{ml}$ (HDL $+\mathrm{LDL}$ ) fraction. Points represent mean \pm SD of quadruplicate determinations. (Inset): Effect of CETP supplementation on plasma optimum CETP activity. CETP activity was determined in all above samples $(5 \mu \mathrm{l})$ as described in Fig. 2 except incubation time was $2 \mathrm{~h}$. The optimum (unidirectional) CE transferred, expressed in nanomoles per milliliter $\cdot h$, was calculated from HDL ${ }^{3} \mathrm{H}-\mathrm{CE}$ specific activity. 
Table II. Effect on Net CE Transfer to VLDL of Supplementing Plasma from Hypertriglyceridemic Subjects $(n=3)$ with Partially Purified CETP

\begin{tabular}{|c|c|c|c|c|}
\hline & \multicolumn{2}{|c|}{ Nonsupplemented plasma } & \multicolumn{2}{|c|}{ CETP-supplemented plasma } \\
\hline & $\begin{array}{l}\text { Net CE transfer } \\
\text { to VLDL }\end{array}$ & $\begin{array}{c}\text { CETP } \\
\text { activity }\end{array}$ & $\begin{array}{l}\text { Net CE transfer } \\
\text { to VLDL }\end{array}$ & $\begin{array}{c}\text { CETP } \\
\text { activity }\end{array}$ \\
\hline & \multicolumn{4}{|c|}{$\mathrm{nmol} / \mathrm{ml} \cdot \mathrm{h}$} \\
\hline \multicolumn{5}{|l|}{ Subject } \\
\hline 1 & 134 & 264 & 276 & 774 \\
\hline 2 & 98 & 206 & 259 & 621 \\
\hline 3 & 76 & 167 & 171 & 537 \\
\hline Mean \pm SD & $103 \pm 29$ & $212 \pm 49$ & $235 \pm 56^{*}$ & $644 \pm 120^{4}$ \\
\hline
\end{tabular}

$10 \mathrm{ml}$ of blood was obtained from overnight-fasted hypertriglyceridemic subjects (mean plasma cholesterol, $4.82 \pm 1.37 \mathrm{mmol} / \mathrm{liter}$, VLDL $\mathrm{Tg} 4.74 \pm 1.26 \mathrm{mmol} / \mathrm{liter}, \mathrm{HDL}$ cholesterol $0.67 \pm 0.25 \mathrm{mmol} / \mathrm{liter}$, LDL cholesterol $2.26 \pm 0.51 \mathrm{mmol} / \mathrm{liter}$ ). Net CE transfer and CETP activity were measured as described in Fig. 6 on native plasma (left panel) and on the same plasma supplemented with CETP $(440 \mu \mathrm{g})$ to increase plasma CETP activity threefold (right panel).

${ }^{\ddagger} P<0.01 ;{ }^{*} P<0.05$ vs. respective measurement in nonsupplemented plasma (paired $t$ test).

The possibility that VLDL concentration limits net CE transfer in normolipidemia was verified by the observation that supplementation of plasma with purified VLDL increased net CE transfer. Conversely, the hypothesis that CETP is rate limiting in hypertriglyceridemia was verified by supplementation of
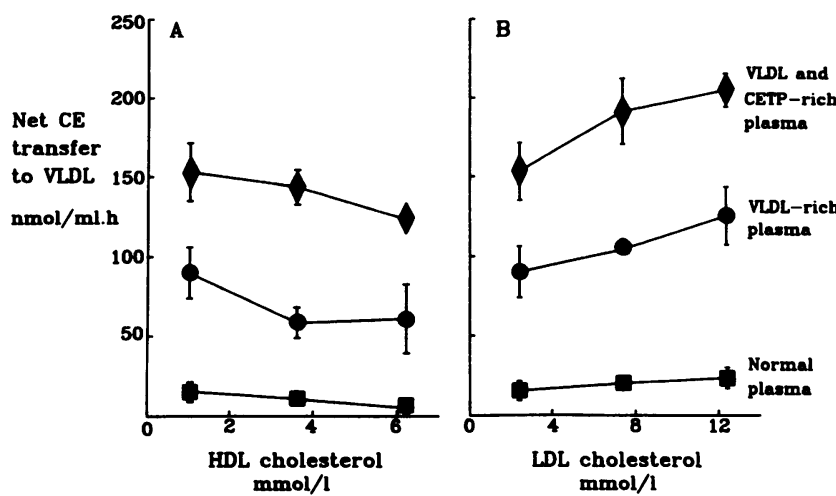

Figure 7. Effect of plasma HDL $(A)$ and LDL $(B)$ concentrations on net CE transfer to VLDL. Fasting plasma ( () was obtained from a normolipidemic subject-cholesterol $4.3 \mathrm{mmol} /$ liter $(166 \mathrm{mg} / \mathrm{dl}), \mathrm{Tg}$ $0.61 \mathrm{mmol} / \mathrm{liter}(54 \mathrm{mg} / \mathrm{dl}), \mathrm{HDL}$ cholesterol $1.20 \mathrm{mmol} / \mathrm{liter}(46$ $\mathrm{mg} / \mathrm{dl})$, CETP activity $193 \mathrm{nmol} / \mathrm{ml} \cdot \mathrm{h}$. Plasma aliquots $(1 \mathrm{ml})$ were supplemented with increasing concentrations of autologous $\operatorname{HDL}(A)$ or LDL $(B)$ as indicated, and incubated at $37^{\circ} \mathrm{C}$ for $4 \mathrm{~h}$. Separate aliquots of plasma were enriched to $5 \mathrm{mmol} / \mathrm{liter}$ VLDL Tg either without $(\bullet)$ or with $(\bullet)$ addition of purified CETP (twofold activity of original plasma), then supplemented with increasing concentrations of $\mathrm{HDL}$ or $\mathrm{LDL}$ and incubated at $37^{\circ} \mathrm{C}$ for $2 \mathrm{~h}$. All samples $(1.4 \mathrm{ml}$, final vol) contained $2 \mathrm{mM}$ E600 as LCAT inhibitor. After incubation, net CE transfer was measured as the increase of CE in the $d<1.006$ $\mathrm{g} / \mathrm{ml}$ fraction (VLDL). Means \pm SD are shown for quadruplicate determinations except where SD bars are concealed by the symbols. Supplementation of HDL or LDL did not significantly (paired $t$ test, two tailed) alter net $C E$ transfer except at the highest concentration of LDL in plasma enriched with both VLDL and CETP $(P<0.05)$.
Table III. Plasma Lipids, Apolipoproteins, and CE Transfer Measurements of Eight Hypertriglyceridemic Subjects before and during Bezafibrate Therapy

\begin{tabular}{lcc}
\hline & \multicolumn{2}{c}{ Week of Treatment } \\
\cline { 2 - 3 } & 0 & 6 \\
\hline Cholesterol (mmol/liter) & $6.0 \pm 0.6^{*}$ & $5.7 \pm 0.7$ \\
Triglycerides (mmol/liter) & $3.91 \pm 1.0$ & $1.90 \pm 0.63^{\ddagger}$ \\
VLDL-Triglycerides (mmol/liter) & $2.91 \pm 0.62$ & $1.08 \pm 0.54^{\ddagger}$ \\
HDL-Cholesterol (mmol/liter) & $0.90 \pm 0.16$ & $1.17 \pm 0.23^{\ddagger}$ \\
LDL-Cholesterol (mmol/liter) & $3.27 \pm 0.68$ & $3.90 \pm 0.70$ \\
Apo AI (mg/ml) & $0.99 \pm 0.08$ & $1.24 \pm 0.14^{\ddagger}$ \\
Apo B (mg/ml) & $1.13 \pm 0.12$ & $0.98 \pm 0.21^{\S}$ \\
Net CE transfer (nmol/ml·6 h) & & \\
to VLDL & $364.4 \pm 46.2$ & $188.3 \pm 96.1^{\prime}$ \\
to LDL & $30.8 \pm 75.0$ & $18.1 \pm 83.3$ \\
Optimum CETP activity & & \\
$\quad$ (nmol/ml $\cdot \mathrm{h})$ & $159.9 \pm 66.3$ & $147.5 \pm 70.2$
\end{tabular}

${ }^{*}$ Mean \pm SD. ${ }^{1} P<0.001{ }^{\ddagger} P<0.002 ;{ }^{8} P<0.05$ vs. week 0 (paired $t$ test).

normal and VLDL-enriched plasma with purified CETP. Increasing the mass of CETP in normolipidemic plasma had no effect on net CE transfer to VLDL. In contrast, the same quantity of CETP added to VLDL-enriched plasma increased net CE transfer more than twofold. The rate-limiting effect of CETP was also demonstrated directly in hypertriglyceridemia. Increasing the mass of CETP in plasma from hypertriglyceridemic subjects significantly enhanced the initially high rate of net $\mathrm{CE}$ transfer. Further evidence for this interpretation is found in data obtained from hypertriglyceridemic subjects treated with bezafibrate. Correction of hypertriglyceridemia reduced net CE transfer towards normal levels but did not affect optimum CETP activity. After this treatment, linear correlation between net CE transfer and VLDL concentration was restored as in the normolipidemic group, while the preexisting correlation between net CE transfer and optimum CETP activity was no longer significant. Our investigations therefore indicate that in normolipidemia, the concentration of $\mathrm{Tg}$-rich lipoproteins in plasma provides the driving force for net CE transfer, while in hypertriglyceridemia, the enhanced rate of net transfer is limited by CETP mass. This suggests that, for hypertriglyceridemic subjects, dietary (23) or genetic (25) factors affecting CETP expression could influence the individual variation in net $\mathrm{CE}$ transfer.

We have demonstrated in this study that stimulation of net CE transfer to the same extent as that observed in hypertriglyceridemia was achieved by supplementation of normal VLDL to normal plasma. Alterations in VLDL composition are therefore not required for these particles to increase net $C E$ transfer. This does not exclude that the reported enrichment of hypertriglyceridemic VLDL with unesterified cholesterol $(13,26)$ could modulate the ability of such particles to accumulate CE (27).

The observation that VLDL concentration drives net CE transfer provides a mechanism to explain the correlations between plasma $\mathrm{Tg}$ concentration and lipoprotein core-lipid compositional abnormalities in hypertriglyceridemia, as well as the reversion of these compositional changes towards nor- 

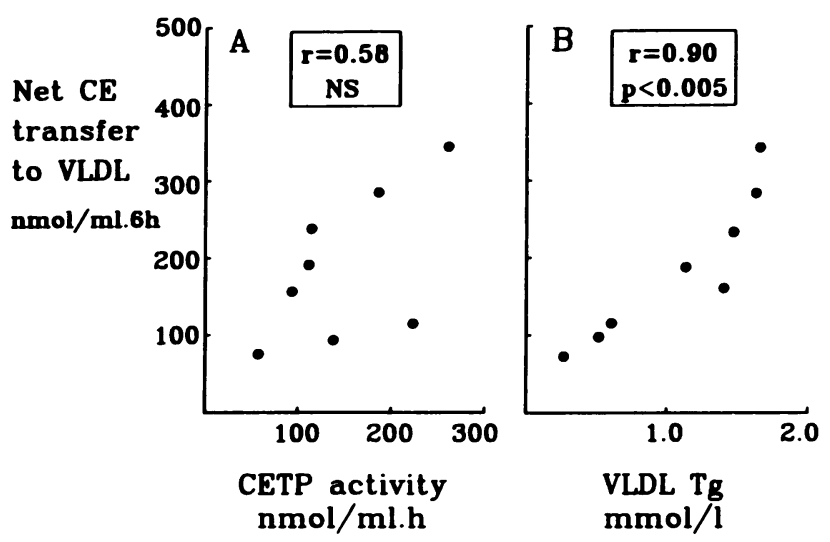

mal after reduction of VLDL concentration by administration of bezafibrate (13). Although plasma HDL CE concentration did not correlate with net CE transfer in either the normolipidemic or the hypertriglyceridemic group, a significant inverse correlation $(r=-0.69, P<0.001)$ was observed when data from both groups were pooled. Thus, accelerated net CE transfer as a result of increased VLDL concentration could explain differences in HDL CE concentration between, but not within, the two groups.

It must also be considered that determination of net $\mathrm{CE}$ transfer in incubated plasma reflects only partially the physiological transfer of neutral lipid. Indeed, the role of factors, e.g., lipolysis which has been shown to enhance CETP activity (28), is not taken into account in such an assay. Therefore, the possibility remains that other parameters contribute in vivo to the regulation of net $\mathrm{CE}$ transfer.

In agreement with the present study, increased plasma net $\mathrm{CE}$ transfer has been reported in other conditions of hypertriglyceridemia. Compared to fasting normal subjects, net $\mathrm{CE}$ transfer was enhanced threefold in dysbetalipoproteinemia (type III hyperlipidemia) (16), and two to threefold during postprandial lipemia $(17,18)$. In both conditions, the enhanced net $C E$ transfer was attributed to a combined stimulatory effect of hypertriglyceridemia and increased activity of CETP (16, 18). Our conclusions, however, are not consistent with the interpretation that net CE transfer is reduced or unchanged in hypertriglyceridemia (5). This discrepancy most likely results from the fact that hypertriglyceridemic groups studied in the previous investigation were small and included subjects with secondary hypertriglyceridemia, as well as individuals receiving lipid-active drugs or with high plasma cholesterol.

In this report, we clarify the mechanisms through which a potentially independent atherogenic risk factor, i.e., CETP, affects lipoprotein core composition in hypertriglyceridemia. This analysis led us to propose that the driving force for net CE transfer is VLDL. As VLDL concentration increases, CETP becomes rate-limiting. Thus, in hypertriglyceridemia, net $\mathrm{CE}$ transfer is limited by CETP and could therefore be affected by factors modulating CETP concentration. We postulate that the relative excess of CETP in plasma of overnight fasted normolipidemic subjects may provide the reserve to satisfy greater need for transfer of neutral lipids during the postprandial stage.

\section{Acknowledgments}

The authors are deeply indebted to Dr. Paul S. Roheim for his critical review of the manuscript, many valuable suggestions and continual

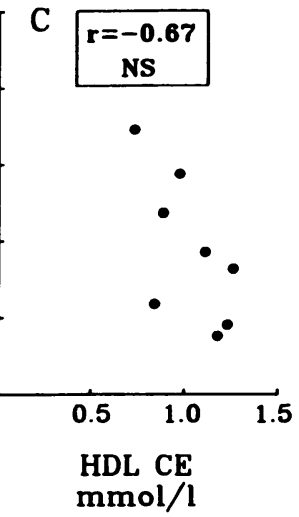

Figure 8. Correlations of net CE transfer to VLDL with optimum CETP activity $(A)$, VLDL $\mathrm{Tg}(B)$, and HDL CE $(C)$ in hypertriglyceridemic subjects $(n=8)$ after 6 wk of bezafibrate therapy. support. Thanks are extended to Drs. Jean Davignon, Ira Goldberg, and Alfredo Lopez for providing the plasma from subjects presented in Table II. We also wish to thank Dr. Charles Sloop for his assistance in preparation of the figures.

This research was supported by a George $S$. Bel Fellowship from the American Heart Association-Louisiana, Inc. (awarded to C. J. Mann), and by grants from the National Institutes of Health (HL-25596) and Leeds Western Area Health Authority (LW74).

\section{References}

1. Morton, R. E., and D. B. Zilversmit. 1983. Inter-relationship of lipids transferred by the lipid-transfer protein isolated from human lipoprotein-deficient plasma. J. Biol. Chem. 258:11751-11757.

2. Albers, J. J., J. H. Tollefson, C.-H. Chen, and A. Steinmetz. 1984. Isolation and characterization of human plasma lipid transfer proteins. Arteriosclerosis. 4:49-58.

3. Tall, A. R. 1986. Plasma lipid transfer proteins. J. Lipid Res. 27:361-367. 4. Barter, P. J., G. J. Hopkins, and G. D. Calvert. 1982. Transfers and exchanges of esterified cholesterol between plasma lipoproteins. Biochem. J. 208:17 .

5. Fielding, P. E., C. J. Fielding, R. J. Havel, J. P. Kane, and P. Tun. 1983. Cholesterol net transport, esterification, and transfer in human hyperlipidemic plasma. J. Clin. Invest. 71:449-460.

6. Brown, M. R., A. Inazu, C. B. Hesler, L. B. Agellon, C. Mann, M. E Whitlock, Y. L. Marcel, R. W. Milne, J. Koizumi, H. Mabuchi, et al. 1989. Molecular basis of lipid transfer protein deficiency in a family with increased high-density lipoproteins. Nature (Lond.). 342:448-451.

7. Inazu, A., M. L. Brown, C. B. Hesler, L. B. Agellon, J. Koizumi, K. Takata, Y. Maruhama, H. Mabuchi, and A. R. Tall. 1990. Increased high-density lipoprotein levels caused by a common cholesteryl-ester transfer protein gene mutation. N. Engl. J. Med. 323:1234-1238.

8. Castelli, W. P., J. T. Doyle, T. Gordon, C. G. Hames, M. C. Hjortland, S. B. Hulley, A. Kagan, and W. J. Zukel. 1977. HDL cholesterol and other lipids in coronary heart disease. The cooperative lipoprotein phenotyping study. Circulation. 55:767-772.

9. Castelli, W. P., R. J. Garrison, P. W. F. Wilson, R. D. Abbott, S. Kalousdian, and W. B. Kannel. 1986. Incidence of coronary heart disease and lipoprotein cholesterol levels. The Framingham Study. JAMA (J. Am. Med. Assoc.). 256:2835-2838.

10. Gordon, D. J., J. Knoke, J. L. Probstfield, R. Superko, and H. A. Tyroler. 1986. High-density lipoprotein cholesterol and coronary heart disease in hypercholesterolemic men: the lipid research clinics coronary primary prevention trial. Circulation. 74:1217-1225.

11. Phillips, N. R., R. J. Havel, and J. P. Kane. 1981. Levels and interrelationships of serum and lipoprotein cholesterol and triglycerides. Association with adiposity and the consumption of ethanol, tobacco, and beverages containing caffeine. Arteriosclerosis. 1:13-24.

12. Nikkila, E. A., M.-R. Taskinen, and T. Sane. 1987. Plasma high-density lipoprotein concentration and subfraction distribution in relation to triglyceride metabolism. Am. Heart J. 113:543-548.

13. Eisenberg, S., D. Gavish, Y. Oschry, M. Fainaru, and R. J. Deckelbaum. 1984. Abnormalities in very low, low, and high density lipoproteins in hypertriglyceridemia: reversal toward normal with bezafibrate treatment. J. Clin. Invest. 74:470-482.

14. Fielding, C. J. 1987. Factors affecting the rate of catalyzed transfer of cholesteryl esters in plasma. Am. Heart J. 113:532-537.

15. Sparks, D. L., J. Frohlich, A. G. Lacko, and P. H. Pritchard. 1989. Rela- 
tionship between cholesteryl ester transfer activity and high density lipoprotein composition in hyperlipidemic patients. Atherosclerosis. 77:183-191.

16. Tall, A., E. Granot, R. Brocia, I. Tabas, C. Hesler, K. Williams, and M. Denke. 1987. Accelerated transfer of cholesteryl esters in dyslipidemic plasma: role of cholesteryl ester transfer protein. J. Clin. Invest. 79:1217-1225.

17. Castro, G. R., and C. J. Fielding. 1985. Effects of postprandial lipemia on plasma cholesterol metabolism. J. Clin. Invest. 75:874-882.

18. Tall, A., D. Sammett, and E. Granot. 1986. Mechanisms of enhanced cholesteryl ester transfer from high density lipoproteins to apolipoprotein B-containing lipoproteins during alimentary lipemia. J. Clin. Invest. 77:1163-1172.

19. Gidez, L. I., G. J. Miller, M. Burstein, S. Slagle, and H. A. Eder. 1982. Separation and quantitation of subclasses of human plasma high density lipoproteins by a simple precipitation procedure. J. Lipid Res. 23:1206-1223.

20. Lowry, O. H., N. J. Rosebrough, A. L. Farr, and R. J. Randall. 1951. Protein measurement with the Folin phenol reagent. J. Biol. Chem. 193:265-275.

21. Deckelbaum, R. J., S. Eisenberg, Y. Oschry, I. Sharon, E. Butbul, and T. Olivecrona. 1982. Reversible modification of human plasma low density lipoproteins towards triglyceride-rich precursors: a mechanism for losing excess cholesterol esters. J. Biol. Chem. 257:6509-6517.

22. Jonas, A., S. A. Sweeny, and P. N. Herbert. 1984. Discoidal complexes of $A$ and $C$ apolipoproteins with lipids and their reactions with lecithin:cholesterol acyltransferase. J. Biol. Chem. 259:6369-6375.
23. McPherson, R., C. J. Mann, A. R. Tall, M. Hogue, L. Martin, R. W. Milne, and Y. L. Marcel. 1991. Plasma concentrations of cholesteryl ester transfer protein (CETP) in hyperlipoproteinemia: relationship to CETP activity and other lipoprotein variables. Arteriosclerosis. 11:797-804.

24. Yen, F. T., R. J. Deckelbaum, C. J. Mann, Y. L. Marcel, R. W. Milne, and A. R. Tall. 1989. Inhibition of cholesteryl ester transfer protein activity by monoclonal antibody. Effects on cholesteryl ester formation and neutral lipid mass transfer in human plasma. J. Clin. Invest. 83:2018-2024.

25. Agellon, L. B., A. Walsh, T. Hayek, P. Moulin, X. C. Jiang, S. A. Shelanski, J. L. Breslow, and A. R. Tall. 1991. Reduced high density lipoprotein cholesterol in human cholesteryl ester transfer protein transgenic mice. J. Biol. Chem. 266:10796-10801.

26. Vakakis, N., T. G. Redgrave, D. M. Small, and W. P. Castelli. 1983 Cholesterol content of red blood cells and low density lipoproteins in hypertriglyceridemia. Biochim. Biophys. Acta. 751:280-285.

27. Morton, R. E. 1988. Free cholesterol is a potent regulator of lipid transfer protein function. J. Biol. Chem. 263:12235-12241.

28. Tall, A. R., D. Sammett, G. M. Vita, R. Deckelbaum, and T. Olivecrona 1984. Lipoprotein lipase enhances the cholesteryl ester transfer protein-mediated transfer of cholesteryl esters from high density lipoproteins to very low density lipoproteins. J. Biol. Chem. 259:9587-9594. 